\section{Assessment of quality of life of Iranian nurses}

\author{
Maryam Aalaa,' Mahnaz Sanjari,' \\ Ali Tootee, ${ }^{1}$ Ghazanfar Mirzabeigi, ${ }^{2}$ \\ Sedighe Salemi \\ 'Endocrinology and Metabolism Research \\ Center, Tehran University of Medical \\ Sciences, Tehran; ${ }^{2}$ Research and \\ Education Department, Iranian Nursing \\ Organization, Tehran, Iran
}

\section{Abstract}

Nurses' Quality Of Life (QOL) may be affected by many different factors that can in turn influence their job competency. The aim of this study was to assess the QOL of Iranian nurses to provide evidence to enable policy makers to take the necessary steps needed to make improvements. Using a cross-sectional study design, we evaluated the QOL of Iranian nurses by the assessment of four health indicators: physical, psychological, social and environmental. A total of 850 nurses from 17 different provinces of Iran were recruited by random sampling. They were requested to complete the World Health Organization QOL-BREF questionnaire. Data were then analyzed. Results indicated that half of the nurses scored in the moderate range, suggesting that they had a reasonably good QOL. They scored considerably higher in terms of physical health indicators and achieved significantly lower scores regarding environmental health issues. Although the $\chi^{2}$ test did not show any significant association between the QOL indicators and different factors such as work experience, gender, job position and patients group. We found a significant association between the subject's position at work in the hospital shift pattern and their overall QOL score. The results of our study showed that more than half the nurses evaluated their QOL to be at a moderate level. The results from this study can be used by policy makers to help make improvements to nurses' QOL that may enhance the quality of care they deliver to their patients. Future research including a group of nurses from over the whole country is essential so that a more representative cohort can be studied. It would also pave the way for the establishment of a QOL database for nurses in Iran that could monitor changes in the nursing population.

\section{Introduction}

It is universally acknowledged that nurses generally have hectic lifestyles and they usually struggle to create and maintain a balance between different aspects of their personal life. They also need to meet their responsibilities, such as health care provision, professional education and workplace management. In addition, they often have to cope with various problems in their job such as staff shortages, work overload and long shifts, which can in turn affect the quality of their services. For that reason, it is important for nurses to be able to cope with these problems so that they are able to provide the best service they can. Therefore, one could argue that nurses' quality of life (QOL) is of great importance to society as it can affect the quality of health care provision.

There are various definitions of QOL depending both on the individual and the society. It has been defined by the World Health Organization (WHO) in 1993 as an individuals' perceptions of living status based on the cultural background and ideological values of the society in which they live and its relevancy to their goals, standards and concerns. ${ }^{1}$ According to this definition, QOL is made up of six different areas: physical health, psychological status, level of independence, personal relationships, physical environment and spiritual wellbeing. King believes that different factors such as socio-economic level, emotionalpsychological status and working status can affect the quality of life of an individual. It has also been argued that quality of life is influenced by family interactions, family support, the individual's role in her/his job, and the role of other family members in their life. Therefore, in general, the type of work one does is considered to be one of the most important factors affecting our QOL. ${ }^{2}$

Over the last decade, the global staff shortage within their profession has posed new problems for nurses. This has meant them having to work long shifts that has in turn exacerbated their difficulties and affected their QOL. ${ }^{3}$ Nurses make up a large proportion of healthcare providers in all health care systems in the world. ${ }^{4}$ Today, the increasing shortage of nurses and the increasing trend of them quitting their jobs are widespread both in the developed and developing countries. ${ }^{5}$ Furthermore, this shortage of nurses has resulted in the failure of policy makers and governments to achieve national and global objectives, goals in health care provision and to promote public health. ${ }^{6}$ This picture could become even more drastic; Roman has predicted that the shortage of nurses could dramatically increase in the years 2015 to $2020{ }^{7}$ Therefore, one could estimate that by 2020 approximately 400,000 nursing jobs will be vacant. ${ }^{8}$ Also, by the year 2010 , more than $40 \%$ of nurses will be over 50 years of age. ${ }^{9,10}$ As a result, nursing shortages could lead to heavier workloads and longer working hours that can in turn affect nurses' Q0L. ${ }^{11,12}$
Correspondence: Sedighe Salemi, Research and Education Department, Iranian Nursing Organization, No 8, Arshad Allay, Karimkhan Ave, Tehran, Iran.

Tel. +98.21.8893.5868 - Fax: +98.21.88906293.

E-mail: salemis2000@yahoo.com; salami@ino.ir

Key words: quality of life, nurse, nursing profession, professional characteristics.

Contributions: Sanjari and Salemi conceived the study and designed it, Aalaa and Sanjari collected data and analyzed them, Sanjari and Tootee drafted the manuscript, Salemi and Mirzabeigi provided critical review of major intellectual content and supervised the writing. All authors gave their final approval for the manuscript to be published.

Acknowledgments: this study was an approved project of the Iranian Nursing Organization with the registration number: 89 / 113/ I N. A. The authors wish to express their gratitude to all the nurses who kindly assisted us with this research. It should be noted that conducting this study would not be possible without the generous support of the nursing board councils.

Received for publication: 3 August 2011.

Revision received: 27 April 2012.

Accepted for publication: 27 April 2012.

This work is licensed under a Creative Commons Attribution NonCommercial 3.0 License (CC BYNC 3.0).

(C) Copyright M. Aalaa et al., 2012

Licensee PAGEPress, Italy

Nursing Reports 2012; 2:e10

doi:10.4081/nursrep.2012.e10

So far, research studies have been conducted on QOL and various instruments have been designed to specifically or generally evaluate it. An overview of studies in this area indicates that the physical health and physical environment had the lowest and highest rates in nurses' quality of life, respectively. In fact, nurses often play several simultaneous roles in their family and the society as a whole. Consequently, they are exposed to many different physical and emotional challenges such as fatigue, insomnia, and emotional problems, which can result in an overall reduction in their QOL. Furthermore, as night shifts and the consequent sleep deprivation is an inextricable part of the duties of many nurses, there is a real concern that nurses may be affected by some degree of different sleep deprivation related ailments. Furthermore, long shifts may result in withdrawal from hobbies, entertainments and social activities, which can worsen their QOL further. ${ }^{13-15}$

Some studies have described Iranian nurses' occupational status in different dimensions. Mirzabeigi and colleagues conducted a 
survey on job satisfaction involving 1,058 Iranian nurses. Results of the study demonstrated that only about $34 \%$ of nurses were satisfied with their jobs. The nurses declared their professional duties, the methods of communication between nursing managers, and their social position as the main reasons for job dissatisfaction. ${ }^{16}$ Also, Shoghi and colleagues conducted a study about workplace abuse and bullying involving Iranian nurses. The result of the study on 1317 nurses illustrated that $87 \%$ and $27 \%$ of them have experienced verbal abuse and physical violence, respectively, during a 6 -month period. ${ }^{17}$ Another study of 216 nurses demonstrated that $55 \%$ of participants had moderate stress levels related to occupational issues. Also, a significant association was found between stress level and job satisfaction. ${ }^{18}$

Another important factor affecting the QOL of nurses is stress in the workplace. Nursing is a career that poses an enormous amount of stress on individuals due to their demanding duties, numerous responsibilities and a variety of complex social issues. ${ }^{19}$ These daily exposures to work-related stress may result in the development of a constellation of psychological and physical health problems. The resultant psychological and physical health issues can, in turn, severely affect nurses' QOL. Furthermore, it could be suggested that sleep deprivation and poor nutrition, which is usually caused by working shifts, play an important role in threatening nurses' health and, thereby, decreasing their QOL. Also, working different hours on fluctuating shift patterns can cause fatigue and influence various aspects of nurses' social life, such as their relationships with their partners, children, friends and co-workers. ${ }^{3}$

\section{History and structure of nursing in Iran}

The first nursing school was founded in Iran in 1915 and by 1916 the 3 -year nursing training course had been officially established. In 1952, the Iran Ministry of Health and Medical Education officially formed a Department for Nursing Affairs and this was the first move towards endorsement of the nursing profession by the government. The first course in nursing was offered by the University of Shiraz in 1967 as a Bachelor's degree in Nursing. Consequently, the organizers of nurse training courses developed the first Master's Degree in Nursing and Doctorate Degree in Nursing in 1946 and 1995, respectively. In 2002, the parliament of the Islamic Republic of Iran passed a bill that allowed the formation of the Iranian Nursing Organization (INO). Since then, the organization has officially been in charge of all affairs concerning nurses in Iran and is their official representative. ${ }^{20,21}$

The INO is accountable for the governance, protection of health and security of nurses, provision of ongoing training, public awareness of nursing responsibilities, adherence to Islamic values, promoting patient respect, full observance of nursing ethics, and establishing professional contacts with other Iranian and international organizations. Furthermore, the INO represents a wide range of other allied health care workers, such as assistant nurses, anesthesia technicians, operating theater technicians and emergency medicine assistants. Nursing staff in Iran fall into different categories, such as Registered Nurses, Nurse Practitioners, Head Nurses, Clinical and Educational Supervisors, and Matrons, according to their academic degree and experience. They can be employed by hospitals, clinics, day care centers and other related health service providers. Terms of employment differ and nurses can be employed for permanent, contractual and vocational training periods. Working hours can differ according to experience and work conditions; usually nurses are expected to work 40-44 h per week. They can apply to work in different private sector health care delivery institutes, such as kindergartens, day care centers and nursing homes, if they fulfill the eligibility criteria.

Undoubtedly, nurses play a key role in health care provision and, therefore, a reduction in their quality of life can damage the quality of care they provide for patients. Therefore, any improvement in the QOL of nurses could have an enormous impact on the health and wellbeing of patients and consequently, lead to health care goals and objectives in different countries being fulfilled more quickly. Furthermore, better care for patients means improving their quality of life and health status, which is the ultimate goal for any health care system. Unfortunately, however, to our knowledge, not enough research has been carried out on nurses' QOL. In particular, in Iran, appropriate strategies and guidelines to improve QOL have not been implemented..$^{22,23}$ The aim of the current study is to evaluate the QOL of nurses based on the criteria defined by the WHO. We intend the results to be used as a basis to trace any future change in the QOL of Iranian nurses. The findings could also be used to adopt national strategies to improve the QOL of nurses in other Middle Eastern countries with similar cultures and hopefully pave the way for further studies in the future.

\section{Materials and Methods}

This cross-sectional study was carried out to evaluate the QOL of nurses from different provinces of Iran where a State Board of Nursing existed. A list of Iranian state hospitals was provided and those with less than 30 nursing staff were excluded to avoid excessive fragmentation. A random sample was then taken and 40 hospitals were chosen from around Iran. A total of 1,200 questionnaires were posted to each Board of Nursing and distributed among the nurses.

During the course of three months (October - December 2010), a total number of 850 questionnaires were returned to the Board of Nursing. The actual response rate amongst the nurses was $70.8 \%$ and the sampling method was a simple random sampling technique. Demographic characteristics of nurses participating in the study are shown in Table 1.

The study was approved by the Iranian Board of Nursing and was registered as 89.113.I.N.0. and approval was given by the organization's ethics committee. Non-Iranian nurses were excluded from the study. All participants had at least two years work experience. Participants filled in both the demo-

Table 1. Demographics and professional characteristics of Iranian nurses $(n=850)$.

\begin{tabular}{lc} 
& N $(\%)$ \\
Gender & \\
Female & $665(78.2)$ \\
Male & $185(31.5)$ \\
Age & \\
$20-30$ & $366(43.1)$ \\
$31-40$ & $308(36.2)$ \\
$41-50$ & $146(17.2)$ \\
$>51$ & $30(3.4)$ \\
\hline Education & \\
MSc & $42(4.9)$ \\
BSc & $745(87.6)$ \\
Associate Diploma & $63(7.4)$ \\
Type of enrollment & \\
Permanent & $431(50.7)$ \\
Contractual & $231(27.2)$ \\
Others & $188(22.1)$ \\
\hline Years of experience & \\
$<10$ & $491(57.8)$ \\
11-20 & $263(30.9)$ \\
21-30 & $95(11.3)$ \\
Position & \\
Nursing director & $8(9.0)$ \\
Educational supervisor & $27(3.2)$ \\
Clinical supervisor & $30(3.5)$ \\
Head nurse & $123(14.5)$ \\
Nursing staff & $74(8.7)$ \\
Registered nurse & $588(69.2)$ \\
\hline Shift work & \\
Morning & $193(22.7)$ \\
Afternoon & $14(1.6)$ \\
Night & $24(2.8)$ \\
Rotation & $619(72.8)$ \\
Patient care & \\
All groups & $443(52.1)$ \\
Children/infants & $170(20.0)$ \\
Mothers & $129(15.2)$ \\
Woman & $108(12.7)$ \\
\hline
\end{tabular}


graphic characteristics form and the WHO QOL-BREF questionnaires. Completion of the questionnaire was taken as consent to participate in the study. A self-reporting questionnaire was used and a representative of the governing board was present when questionnaires were being completed to provide any explanations required.

The questionnaire was made up of two parts. The first was designed to collect demographic information including age, gender, nursing qualification (Associated, Bachelor and Master Degree), terms of employment (permanent, contractual, other), experience, hospital ward, working shifts (day, afternoon, night and rotating shift), professional rank and position (Matron, Educational Supervisor, Clinical Supervisor, Head Nurse and Nurse) and the characteristics of their patients (children/ infants, men, women, all groups of patients).

In the second part, the WHO QOL-BREF questionnaire was used to evaluate nurses' QOL. This questionnaire is one of the existing standard questionnaires for the assessment of QOL developed by the WHO. It includes 26 questions and has four different sections. Two separate questions (questions 1 and 2) ask about quality of life in general. The other 24 questions measure a particular aspect of physical health (questions 3, 4, 10, 15, 16, 17 and 18), mental health (questions 5, 6, 7, 11, 19 and 26), social health (questions 20, 21 and 22 ), and environmental health (questions 8,9 , $12,13,14,23,24$ and 25$)$. It is worthy of note that 2 questions out of the total of 26 were designed to investigate how the subjects generally rated their QOL and how satisfied they were with their health status. This information was provided according to the instructions of the standard questionnaire.

The physical health field consisted of five different domains: motivation, daily living activities, energy levels, working capacity, pain and discomfort, and sleep. Mental health domain questions included body image, negative and positive feelings, self-esteem, thoughts, learning, memory and concentration, religion and mental status. In the social relationship domain, topics such as interpersonal communication, social support and sexual satisfaction were assessed. The environmental health domain was designed to investigate financial and physical security, health and social support, quality of living area, opportunities for learning new skills and information, recreational activities, physical environment (e.g. noise, air pollution), and transportation.

The Persian translation of this questionnaire is available on the World Health Organization website. The questionnaire was used without any changes. ${ }^{24,25}$ Psychometric characteristics of the translated questionnaire indicated its validity to be used for an Iranian population. The correlation coefficient in test- retest within two weeks in four domains was $75 \%$ to $84 \%$. Structural validity indicators pointed out equal validity of the instrument for an Iranian population. ${ }^{26}$ Interestingly, the questionnaires focused exclusively on the period of the previous four weeks.

Each question in the questionnaire had five answer choices ranging from very dissatisfied to very satisfied, never to completely and very bad to very good grades. Subjects would score between 1 to 5 points for each question. Based on the negative and positive connotation of each question in terms of satisfaction with life, a scoring system ranging from 1 to 5 or the opposite (5-1) was employed according to the instructions of the questionnaire. Scores of each category were reported separately. Different scores were not compiled together because of the difference in the fields of the questionnaire..$^{26}$

All statistical analysis was completed using descriptive statistics and $\chi^{2}$ test. Data were analyzed using SPSS software (version 16). $\mathrm{P}<0.05$ was considered significant.

\section{Results}

Demographic data and professional characteristics are shown in Table 1. Age ranged from 20 to 60 years. Most of the participants were aged between 20-30 years of age (43.1\%). A great proportion of nurses held a bachelor's degree in science (87.6\%); 50.7 percent were employed on a permanent basis. A great major- ity of the subjects worked in rotating shifts (72.8) and a considerable number of them were from Tehran (24\%) and Fars (20\%) provinces. Minimum and maximum duration of work experience of the participants was two and 30 years, respectively, (mean 10.3 \pm 7.5 years). Minimum and maximum of working hours were 175 and 450 h per month, respectively, with a mean $228.4 \pm 9.7 \mathrm{~h}$. Two hundred and twenty-two nurses did not work overtime and the cumulative overtime working hours was 333 hours per month. The subjects worked in 18 different types of hospital ward with the majority working in the emergency department (16\%) and intensive care unit (13\%). More than $52 \%$ of nurses who completed the questionnaire took care of all groups of patients.

As far as the indicators of QOL are concerned, the physical health field had the highest mean (13.8 \pm 2.7$)$ and the lowest mean was related to environmental health $(11.2 \pm 2.6)$ (Table 2). The frequency of 2 separate questions showed that $45.3 \%$ of nurses evaluated their QOL as not bad/not good and $44.1 \%$ were completely satisfied with their health status (Table 3).

As for each individual question, the highest mean was related to questions How much medical support do you need to perform your daily tasks? (3.95) and How much physical pain prevents you from your daily duties? (3.68); the lowest mean was related to the questions How much leisure time do you have? (2.01) and How satisfied are you with your access to your required information? (2.71) (Table 4).

Table 2. Mean and standard deviation of quality of life domains $(n=850)$.

\begin{tabular}{lcc} 
Domains & Mean and SD & Interval \\
Physical health & $13.8 \pm 2.7$ & $4-20$ \\
Psychological health & $12.6 \pm 2.8$ & $4-20$ \\
\hline Environmental health & $11.2 \pm 2.6$ & $4-20$ \\
Social relationship & $13.0 \pm 3.2$ & $4-20$ \\
\hline
\end{tabular}

SD, standard error.

Table 3. Frequency of two separate questions of quality of life $(\mathbf{n}=\mathbf{8 5 0})$.

\begin{tabular}{|c|c|c|c|c|c|}
\hline $\begin{array}{l}\text { Frequency of } \\
\text { questions } \\
\text { N (\%) }\end{array}$ & Very good & Good & $\begin{array}{l}\text { Neither poor, } \\
\text { nor good }\end{array}$ & Poor & Very poor \\
\hline \multirow{2}{*}{$\begin{array}{l}\text { How would you } \\
\text { rate your quality } \\
\text { of life? }\end{array}$} & $34(4.0)$ & $331(38.9)$ & 385 (45.3) & $84(9.9)$ & $16(1.9)$ \\
\hline & $\begin{array}{c}\text { Very } \\
\text { satisfied }\end{array}$ & Satisfied & $\begin{array}{l}\text { Neither } \\
\text { satisfied nor } \\
\text { dissatisfied }\end{array}$ & Dissatisfied & $\begin{array}{c}\text { Very } \\
\text { dissatisfied }\end{array}$ \\
\hline $\begin{array}{l}\text { How satisfied } \\
\text { are you with } \\
\text { your health? }\end{array}$ & $59(6.9)$ & 375 (44.1) & 239 (28.1) & $135(15.9)$ & $42(4.9)$ \\
\hline
\end{tabular}


$\chi^{2}$ tests showed no significant association between the scores of different areas of quality of life and indicators such as work experience, gender, terms of employment and patient groups who received care. However, a significant association was found between some of the areas of QOL and other indicators such as working shifts and nursing position in the hospitals (Table 5). In physical, environmental and social relationship domains and their relationship with positions and shifts, the nurse directors had the highest mean; the lowest mean was associated with the registered nurses. In the area of mental health and its relationship to the nurses' position, nurse directors scored the highest average; the highest average related to work shifts was associated with nurses working the evening shift (Table 6).

\section{Discussion}

The results of this study demonstrated that nearly half of the nurses evaluated their QOL as moderate and were satisfied with their health status. Results of similar studies assessing the QOL of nurses on psychiatric wards have demonstrated similar results; more than half of the nurses evaluated their QOL as moderate and only $38.5 \%$ of them were completely satisfied with their health status. ${ }^{15}$

Results of this study also indicated that nurses working on psychiatric wards had the lowest quality of life; this agrees with previous studies conducted elsewhere. The results of our study agreed with those of the studies conducted on other Iranian healthcare professionals. In a study conducted by Nejat $e t$ al. on the QOL of resident medical officers of Tehran hospitals, it was concluded that approximately half $(41.1 \%)$ of the residents questioned evaluated their QOL as moderate and half of them (51.5\%) were quite satisfied with their health status. $^{27,28}$

Therefore, it could be suggested that the results of the evaluation of the QOL of nurses in this study was similar to that of the resident medical officers of Tehran hospitals. This might be due to the fact that the majority of nurses surveyed were employed by hospitals in the province of Tehran (24\%). However, our findings indicate that nurses complained much more about problems such as sleep deprivation, nutritional problems and a difficult social life than other health care professionals in similar settings. ${ }^{29}$

In addition, the results of this study indicated that the highest mean value of the quality of life was associated with physical health and the lowest was related to environmental health. One could suggest that this finding is similar to that of the study conducted by Fallahi et al. on a cohort of psychiatric nurses. The results of the study demonstrated that the most highly scored indicator of the quality of life was that related to physical health and family issues; the area of leisure activities scored the lowest. ${ }^{15}$

Several studies have demonstrated that physical health is the most important indicator of quality of life. ${ }^{14}$ In a study evaluating the QOL of nurses in Chile, results indicated that social life (77.38) and physical health (54.56) were the best and the worst areas, respectively. These results might suggest that physical health is generally low among Chilean nurses, and that evaluation of social life, interpersonal

Table 4. Frequency and mean of nurses quality of life questions $(n=850)$.

\begin{tabular}{|c|c|c|c|c|c|c|c|}
\hline No & Questions & An extreme & $\begin{array}{l}\text { Very } \\
\text { much }\end{array}$ & $\begin{array}{l}\text { A moderate } \\
\text { amount }\end{array}$ & A little & Not at all & Mean \\
\hline 1 & $\begin{array}{l}\text { To what extent do you feel that physical pain prevents you from doing what } \\
\text { you need to do? }\end{array}$ & 0.9 & 1.2 & 30.1 & 37.3 & 21.4 & 3.68 \\
\hline 2 & How much do you need any medical treatment to function in your daily life? & 0.9 & 7.3 & 22.1 & 35.1 & 34.6 & 3.95 \\
\hline 3 & How much do you enjoy life? & 5.3 & 17.6 & 51.1 & 19.8 & 6.2 & 2.94 \\
\hline 4 & To what extent do you feel your life to be meaningful? & 6.1 & 24.2 & 42.6 & 18.7 & 8.4 & 3.01 \\
\hline 5 & How well are you able to concentrate? & 4.7 & 22.2 & 50.7 & 18.4 & 4.0 & 3.5 \\
\hline 6 & How safe do you feel in your daily life? & 4.5 & 23.1 & 44.8 & 19.3 & 8.4 & 2.69 \\
\hline 7 & How healthy is your physical environment? & 3.4 & 11.6 & 46.8 & 26.6 & 11.5 & 2.69 \\
\hline 8 & Do you have enough energy for everyday life? & 8.2 & 22.9 & 40.6 & 23.6 & 4.6 & 3.07 \\
\hline 9 & Are you able to accept your bodily appearance? & 21.4 & 20.0 & 35.5 & 14.8 & 8.2 & 3.32 \\
\hline 10 & Have you enough money to meet your needs? & 6.4 & 14.4 & 39.8 & 21.2 & 18.4 & 2.69 \\
\hline 11 & How available to you is the information that you need in your day-to-day life? & 1.8 & 12.1 & 47.6 & 32.0 & 6.5 & 2.71 \\
\hline 12 & To what extent do you have the opportunity for leisure activities? & 0.8 & 2.6 & 25.6 & 39.1 & 31.9 & 2.01 \\
\hline 13 & How well are you able to get around? & 17.2 & 45.2 & 29.8 & 6.6 & 1.3 & 3.70 \\
\hline 14 & How satisfied are you with your sleep? & 2.9 & 31.8 & 27.8 & 26.6 & 10.9 & 2.89 \\
\hline 15 & How satisfied are you with your ability to perform your daily living activities? & 6.8 & 42.8 & 30.8 & 15.8 & 3.8 & 3.33 \\
\hline 16 & How satisfied are you with your capacity for work? & 10.7 & 47.1 & 28.2 & 11.4 & 2.6 & 3.52 \\
\hline 17 & How satisfied are you with your abilities? & 12.0 & 43.9 & 30.6 & 9.6 & 3.9 & 3.50 \\
\hline 18 & How satisfied are you with your personal relationships? & 9.9 & 49.4 & 30.8 & 8.9 & 4.0 & 3.49 \\
\hline 19 & How satisfied are you with your sex life?* & 4.8 & 31.2 & 19.1 & 6.2 & 7.2 & 3.30 \\
\hline 20 & How satisfied are you with the support you get from your friends? & 3.3 & 33.4 & 42.2 & 14.5 & 6.6 & 3.12 \\
\hline 21 & How satisfied are you with the conditions of your living place? & 8.5 & 38.6 & 30.5 & 14.6 & 7.9 & 3.25 \\
\hline 22 & How satisfied are you with your access to health services? & 5.3 & 35.4 & 34.0 & 19.2 & 6.1 & 3.15 \\
\hline 23 & How satisfied are you with your mode of transportation? & 4.7 & 30.7 & 29.1 & 20.0 & 15.5 & 2.89 \\
\hline 24 & $\begin{array}{l}\text { How often do you have negative feelings, such as blue mood, despair, } \\
\text { anxiety, depression? }\end{array}$ & 4.4 & 28.2 & 42.4 & 19.1 & 6.0 & 3.06 \\
\hline
\end{tabular}

"582 nurses did not answered to this question. 
interactions, and environmental issues could be high in that country. ${ }^{13}$

It is often argued that playing several different roles in society (partner, mother or father, and nurse), poses a great burden on nurses and this is interlinked with emotional problems, conflicts, chronic fatigue, insomnia, and other related issues. ${ }^{13}$ However, our study indicated otherwise, and it could be suggested that the lower Q0L among Iranian nurses stems from the notion that they rated security, public transport, commuting distance from home to work, the quality of accommodation, and access to recreational and sport facilities very poorly. ${ }^{30}$ Nurses working in hospitals in Chile, however, painted a quite different picture. Chilean nurses ranked the above mentioned public services quite highly and they seemed satisfied with them. In contrast, the results of a study conducted on Iranian resident medical officers working for hospitals in Tehran demonstrated that those who scored poorly in terms of quality of life, described public services such as public transportation as being of an extremely low standard. ${ }^{28}$ This could support the argument that defective public services in Tehran play a key role in quality of life issues among nurses.

One of the most important findings of the current study was that the QOL of the study subjects was significantly associated with their working shifts. Nurses who worked in the morning shifts achieved higher scores in QOL. Bagheri et al. have also demonstrated that sleep related problems can damage health and thereby worsen QOL. ${ }^{14}$ Therefore, one could suggest that the higher score of the QOL of nurses who work morning shifts stems from their better sleep quality. A study conducted by Borges et al. investigated the effect of working shifts on sleep cycles and sleep patterns. Results of the study demonstrated that average duration of sleep during a night shift was 208.6 min, after work sleep duration was $138.7 \mathrm{~min}$, average duration of sleep the first night after a night shift was $318.5 \mathrm{~min}$, and the average night's sleep during days off was 310.4 min. ${ }^{31}$ Furthermore, another study by Newy et al. has demonstrated that nurses working night shifts suffered from physical stress, as well as emotional, social, and family problems more frequently than those with different working patterns, particularly morning shifts. ${ }^{32}$

Several different studies have also concluded that night shifts decrease the QOL of nurses because it disturbs sleep, eating patterns and the circadian rhythm..$^{33,34}$ Nurses working at night face more stress than those who work on the morning shifts. ${ }^{35}$ On the other hand, nurses who often work night shifts usually fail to get together and socialize with their family and friends as they need to rest during the day, and this in turn worsens their QOL. ${ }^{36}$ The results of a different study have confirmed that although the nurses working changing shifts enjoyed a better quality of life compared to those who worked only night shifts, their QOL was considerably lower compared to those who worked only daytime shifts, ${ }^{14}$ and this agrees with our results.

Similarly to previous reports, our study showed that QOL is associated with the professional position of nurses. Our results indicated that nurse directors who had been regularly working during the daytime, achieved the highest QOL score and nurses who worked regular night shifts obtained the lowest. In this regard, Khoshknab et al. has also concluded that head nurses gained higher scores in terms of the family aspects of QOL compared with other nurses. ${ }^{15}$ In spite of this, a study by Evans and colleagues has indicated that there is no significant association between nurses' professional position and their QOL. ${ }^{31}$

\section{Conclusions}

Research conducted on the QOL of healthcare providers, especially nurses, can improve health care delivery to the public. Therefore, any study on nurses' QOL should receive generous funding and support from policy makers and politicians. Although the findings of the current study may fall short of representing the overall QOL of nurses in Iran, it can provide a solid baseline for further research in the field. Many of the problems and issues affecting the overall QOL of nurses, such as nursing staff shortages, long working hours, work-related stress, intimidation in the work place, deprivation of social activities and other factors should be addressed by the health care system and policy makers in order to improve the overall delivery of health care.

This study was limited by the selection of cases as participants were selected from hospitals with a high number of nurses. This had been decided to make it easier for the Nursing Board of the Islamic Republic of Iran to follow up study subjects. It may be argued that including hospitals with a small number of nurses could make the cohort more representative of nurses working in Iran. Furthermore, considering the fact that only hospitals from 17 provinces (out of 31) of Iran were included, expanding the study to a wider area could make the results more valid. Therefore, further research on a larger and more representative sample of nurses from more provinces of Iran, and including small and regional hospitals, is warranted to obtain a better profile of the QOL of Iranian nurses.

Table 5. Mean and standard deviation of nurse's quality of life according to the position of nurses $(\mathbf{n}=850)$.

\begin{tabular}{lcccc}
$\begin{array}{l}\text { Domain/ factors } \\
\text { Mean, SD }\end{array}$ & Physical health & $\begin{array}{c}\text { Psychological } \\
\text { health }\end{array}$ & $\begin{array}{c}\text { Environmental } \\
\text { health }\end{array}$ & $\begin{array}{c}\text { Social } \\
\text { relationship } \\
\text { health }\end{array}$ \\
Nursing director & $15.1 \pm 2.3$ & $13.8 \pm 2.6$ & $12.4 \pm 2.5$ & $15.4 \pm 2.7$ \\
Educational supervisor & $14.3 \pm 2.5$ & $12.9 \pm 2.5$ & $12.0 \pm 3.0$ & $13.3 \pm 2.6$ \\
\hline Clinical supervisor & $14.9 \pm 2.2$ & $13.4 \pm 1.9$ & $11.9 \pm 2.3$ & $13.9 \pm 2.4$ \\
Head nurse & $14.5 \pm 2.4$ & $12.7 \pm 2.7$ & $11.8 \pm 2.5$ & $13.6 \pm 2.8$ \\
\hline Staff & $13.8 \pm 2.4$ & $12.6 \pm 2.8$ & $11.5 \pm 2.6$ & $13.2 \pm 3.3$ \\
Nurse & $13.5 \pm 2.7$ & $12.5 \pm 2.8$ & $10.9 \pm 2.5$ & $12.9 \pm 3.3$ \\
\hline P< & 0.000 & 0.021 & 0.000 & 0.013 \\
$\chi^{2}$ & 19.409 & 5.298 & 20.562 & 6.223 \\
\hline
\end{tabular}

Table 6. Mean and standard deviation of nurse's quality of life according to working shift of nurses $(n=850)$.

\begin{tabular}{lcccc}
$\begin{array}{l}\text { Domain/Factors } \\
\text { Mean, SD }\end{array}$ & $\begin{array}{c}\text { Physical } \\
\text { ealth }\end{array}$ & $\begin{array}{c}\text { Psychological } \\
\text { health }\end{array}$ & $\begin{array}{c}\text { Environmental } \\
\text { health }\end{array}$ & $\begin{array}{c}\text { Social } \\
\text { relationship } \\
\text { health }\end{array}$ \\
Morning shift & $14.5 \pm 2.5$ & $12.9 \pm 2.5$ & $11.7 \pm 2.4$ & $13.5 \pm 2.6$ \\
Evening shift & $14.2 \pm 3.3$ & $13.2 \pm 3.0$ & $11.8 \pm 2.6$ & $13.7 \pm 3.4$ \\
\hline Night shift & $13.2 \pm 3.3$ & $12.5 \pm 2.4$ & $10.9 \pm 2.2$ & $13.1 \pm 2.9$ \\
Circulating shift & $13.6 \pm 2.6$ & $12.4 \pm 2.8$ & $11.0 \pm 2.6$ & $12.9 \pm 3.3$ \\
\hline$P<$ & 0.000 & 0.056 & 0.000 & 0.038 \\
$\chi^{2}$ & 14.616 & 3.660 & 12.386 & 4.299 \\
\hline
\end{tabular}

SD, standard error. 
2001.

\section{References}

1. WHO. User manual - Measuring quality of Life. Geneva: World Health Organization; 1997. Available from: http://www.who.int/ mental_health/media/68.pdf

2. King I. Quality of life and goal attainment nursing. Nurs Sci Q 1994;7:29-32.

3. Capodaglio EM, Di Liddo E. Subjective aspects of quality of life in hospital workers. G Ital Med Lav Ergon 2007;29(1 Suppl A):A24-9.

4. Chiu MC, Wang MJ, Lu CW, et al. Evaluating work ability and quality of life for clinical nurses in Taiwan. Nurs Outlook 2007;55:318-26.

5. Nal Council of Nurses. Positive practice environments: quality workplace $=$ quality patient care. Available from: www.icn.ch/ indkit2007.pdf

6. Hong L, Alison E, While K. Barriball L. Job satisfaction among nurses: a literature review. Int J Nurs Stud 2005;42:211-27.

7. Roman L. Nursing shortage: looking to the future. RN 2008;71: 43-6, 38-41.

8. Murray MK. The nursing shortage. JONA 2002;3:79-84.

9. Buerhaus P, Staiger D, Auerbach D. Implications of an aging RN workforce. JAMA 2000;283:2948-54.

10. Spratley E, Johnson A, Sochalski J, et al. The registered nurse population March 2000 findings. National Sample Survey of Registered Nurses, US Department of Health and Human Services, Health Resources and Service Administration, Bureau of Health Professions, Division of Nursing 2000:7-8. http://bhpr.hrsa.gov/ healthworkforce/rnsurveys/rnsurvey2000.p df

11. Joint Commission on Accreditation of Healthcare Organizations (JCAHO). Staffing shortages and quality of care. Available from: http://www.jointcommission.org/The Joint_Commission_-_Helping_Health_ Care_Organizations_Help_Patients_/

12. Kohn LT, Corrigan J, Donaldson MS. To err is human: building a safer system. Washington, DC: National Academy Press;
13. Andrades Barrientos L, Valenzuela Suazo S. Quality of life associated factors in Chileans hospitals nurses. Rev Latino-am Enfermagem 2007;15:480-6.

14. Shao MF, Chou YC, Yeh MY, Tzeng WC. Sleep quality and quality of life in female shift-working nurses. J Adv Nurs 2010;66: 1565-72.

15. Fallahee Khoshknab M, Karimloo M, Rahgoy A, Fattah Moghaddam L. Quality of life and factors related to it among psychiatric nurses in the university teaching hospitals in Tehran. Hakim Res J 2007;9: 24-30

16. Mirzabeigi Gh, Salemi S, Sanjari M, et al. Job Satisfaction among Iranian Nurses. HAYAT 2009;15: 86.

17. Shoghi M, Sanjari M, Shirazi F, et al. Workplace violence and abuse against nurses in hospitals in Iran. Asian Nurs Res 2008;2:184-93.

18. Mojdeh S, Sabet B, Doosti Irani M, et al. Relationship of nurse's stress with environmental-occupational factors. Iranian J Nurs Midwifery Res 2008;13:1-5.

19. Schulz M, Damkroger A, Voltmer E, et al. Work-related behavior and experience pattern in nurses: impact on physical and mental health. J Psychiatr Mental Health Nurs 2011;18:411-7.

20. Salsali M. The development of nursing education in Iran. Int History Nurs J 2000;5:58-63.

21. Adib Hajbaghery M, Salsali M. A model for empowerment of nursing in Iran. BMC Health Serv Res 2005;5:24

22. Haber J, Krainovich-Miller B, McMahon AL, Price-Hoskins P. Comprehensive psychiatric nursing, 5th ed. St. Louis, MO: Mosby; 1997.

23. Hsu MY, Kernohan G. Dimensions of hospital nurses' quality of working life. J Adv Nurs 2006;54:120-31.

24. WHO QOL group. Measuring quality of life; The development of the World Health Organization Quality of Life Instrument (WHO QOL); 1992. Available from: http:// www.who.int/mental_health/media/68.pdf 25. WHO QOL group. WHO QOL-BREF Intro- duction, Administration and scoring. Field Trial version; 1996. Available from: http:/www.who.int/mental_health/media/e $\mathrm{n} / 76 . p d f$

26. Nedjat S, Montazeri A, Holakouie K, et al. Psychometric properties of the Iranian interview-administered version of the World Health Organization's Quality of Life Questionnaire (WHO QOL-BREF): a population-based study. BMC Health Serv Res 2008;8:61.

27. Nedjat S, Hosseinpoor AR, Forouzanfar $\mathrm{MH}$, et al. Decomposing socioeconomic inequality in self-rated health in Tehran. $\mathrm{J}$ Epidemiol Commun Health 2012;66:495500.

28. Nedjat S, Montazeri A, Holakouie K, et al. Quality of Life of Tehran's Population by WHO QOL-BREF questionnaire in 2005. Hakim Res J 2007;10:1-8.

29. Wilson JL. The impact of shift patterns on healthcare professionals. J Nurs Manag 2002;10:211-9.

30. Evans DR, Pellizzari JR, Culbert BJ, et al. Personality, marital and occupational factors associated with quality of life. J Clin Psychol 1993;49:477-85.

31. Borges FN, Fischer FM. Twelve-hour night shifts of healthcare workers: a risk to the patients. Chronobiol Int 2003;20:351-60.

32. Newey CA, Hood BM. Determinants of shift-work adjustment for nursing staff: the critical experience of partners. J Prof Nurs 2004;20:187-95.

33. Nachreiner F. Individual and social determinants of shift work tolerance. Scan J Work Environ Health 1998;24:35-42.

34. Bohle P, Tilley A. Early experience of shift work: influences on attitudes. Occup Organitational Psychol 1998;71:61-79.

35. Pafaro R, De Martino M. Estudio del estrés del enfermero con doble jornada de trabajo en un hospital de oncología pediátrica de Campinas. Rev Esc Enfermagem USP 2004;38:152-60.

36. Saupe R, Nietche E, Cestari M, et al. Calidad de vida de los estudiantes de enfermería. Rev Latino-am Enfermagem 2004;12:636-42. 